
D:\Nsurg \Vol. 24, No. 3, Jul. - Sep., 2020\Nsurg-4.Doc
Fig. 1-2 Color
(A)
P. $289-295 \quad$ II

ORIGINAL ARTICLE

\title{
Caries Spine: A Comparative Study between Medical Management Alone with Combined Medical and Surgical Management
}

\author{
SALEEM SHAH, FARRUKH JAVEED, LAL REHMAN \\ ALI AFZAL, MUNAWAR ALI, SHAKEEL AHMED \\ Department of Neurosurgery, Jinnah Postgraduate Medical Centre, Karachi-Pakistan \\ DOI: $10.36552 /$ pjns.v24i3.428
}

\begin{abstract}
Objective: To compare short term outcome of combined surgical and medical management versus medical management alone in caries spine.

Material and Methods: This study was conducted from August 2015 to August 2018, on 68 patients randomly divided into two groups of 34 each. All were diagnosed cases of Caries spine based on history, clinical examination, ESR and imaging appearances. Group A underwent surgical intervention along with AntiTuberculous Treatment (ATT) while Group B received medical treatment (ATT) alone. Outcome was assessed at six months by Frankel grading.
\end{abstract}

Results: There were 37 (54.41\%) males and 31 (45.59\%) females with mean age of $34.84 \pm 10.6$ years. The thoracic spine was the commonest site in 33 (48.5\%) patients, followed by lumbar in 20 (20.8\%), dorso-lumbar in seven (10.3\%) and cervical in four (5.88\%) patients. The ESR fell from $85 \mathrm{~mm} / \mathrm{hr}$ to $24.46 \mathrm{~mm} / \mathrm{hr}$ in Group A and to $41.92 \mathrm{~mm} / \mathrm{hr}$ in Group B $(p=0.0124)$. Overall improvement in Frankel grade was seen in $25(73.5 \%)$ patients in Group A and $12(35.3 \%)$ in group B. In group A, improvement seen from grade A in two (8\%), grade B in three (12\%), grade $C$ in $12(48 \%)$, Grade D in seven $(28 \%)$ patients, $(p=0.000)$ while eight $(23.5 \%)$ patients remained same and only one (2.5\%) deteriorated from baseline neurological status. In Group B, 16 (47\%) patients remained same and six (17.6\%) deteriorated. Major complications encountered were respiratory infections in four (10\%) and wound infection in two (5\%) patients while none expired.

Conclusion: Surgery combined with antituberculous therapy was found to be beneficial in patients suffering from caries spine and to be recommended to patients desiring rapid recovery.

Keywords: Caries spine, Anti tuberculous therapy, Surgical treatment, Frankel grading.

Abbreviations: ATT: Anti-Tuberculous Treatment. WHO: World Health Organization. CT: Computed Tomography. PCR: Polymerase Chain Reaction. MRI: Magnetic Resonance Image.

\section{INTRODUCTION}

Tuberculosis (TB) is endemic in underdeveloped and developing countries with spinal TB is being the most common and dangerous extra-pulmonary site, accounting for 50 to $60 \% .{ }^{1}$ According to World Health Organization (WHO), annually 6 million become ill with TB and 2 million die from it. Pakistan ranks $6^{\text {th }}$ globally, with a WHO estimated incidence rate of 181 cases per 100000 persons and 272000 new cases annually. ${ }^{2}$

The entire human spine can be involved with common sites being the lower thoracic and upper lumbar levels. ${ }^{3}$ Caries spine is a diagnostic challenge, usually presenting at an advance stage. ${ }^{4}$ Clinical manifestation favors the diagnosis, however a diagnosis needs confirmation by cultures of blood, 
ESR, then bone biopsy, either by an open or percutaneous procedure and radiographic changes on computed tomography (CT) and magnetic resonance image (MRI) findings. The polymerase chain reaction (PCR) has facilitated the diagnosis and management of tuberculosis. ${ }^{5}$

Management of caries spine has remained controversial and divided between those who favor the exclusive medical means of treatment and others who support surgical intervention along with medical treatment. Adequate rest and anti-tuberculous therapy is the cornerstone of management. However, it is advocated that surgical debridement of tuberculosis lesion hastens patient recovery and delays spinal deformity. Terry and James showed that surgery facilitated faster reduction in treatment duration compared to conservative treatment alone, promoting faster bone fusion. ${ }^{6}$ Despite revolutionary improvements in surgery, patients with caries spine can be treated conservatively in a vast majority of cases. ${ }^{7}$ Because of the rise in cases of caries spine and its impact as a major health burden in a resource limited country like ours, we conducted this study to compare treatment options and devise parameters for future research and management.

\section{MATERIAL AND METHODS}

\section{Study Setting}

This study was conducted at the Department of Neurosurgery, Jinnah Postgraduate Medical Center (JPMC), Karachi from August 2015 to August 2018. Institutional Review Board (IRB) approval was taken along with informed and written consent.

\section{Inclusion Criteria}

Patients with spinal tuberculosis admitted through the outpatient department were included in this study. Patients aged $>15$ years of either gender, having caries spine with or without cord compression and involving any spinal level were included.

\section{Exclusion Criteria}

Patients having major neurological deficit, operated elsewhere, having drug resistant TB and with systemic involvement were excluded.

\section{Clinical Assessment and Neurological Assessments}

The diagnosis was made on the basis of history, clinical features, ESR, plain x-rays spine and MRI spine. All patients underwent full clinical assessment and neurological status was assessed according to Frankel grading. All patients were investigated with baseline investigations, including Complete Blood Count, Erythrocyte Sedimentation Rate and Liver Function Tests; special imaging investigations such as CT and MRI spine were done to evaluate the level(s) of lesion and for surgical planning.

\section{Patient Groups and Surgical Techniques}

Sixty eight patients were randomized into two groups with 34 patients in each group. Group A underwent surgical intervention along with ATT according to radiological and clinical presentation while group B was treated only with medical treatment along with other conservative measures (strict bed rest and immobilization).Six patients who deteriorated while on medical treatment and developed neurological deficits were operated as mandated. Surgery constituted decompression followed by grafting and fixation with technique dependent on involved spinal level. For cervical lesions, we performed an anterior decompression and plating while in thoracic lesions we did decompression with Webb Morley technique and we did decompression and transpedicular screw fixation in lumbar lesions. ${ }^{6}$

\section{Clinical Management}

All patients received standard ATT as a combination of four drug therapy containing Rifampicin, Isoniazid, Pyrazinamide (PZA) and Ethambutol in accordance to their body weight. Pyridoxine was added to prevent peripheral neuropathy. Ethambutol and PZA were excluded after two months while Rifampicin and $\mathrm{INH}$ were continued. Patients were followed up for six months for complications and outcome was assessed as good or poor based on the Frankel grading.

\section{Data Analysis}

Data was entered in SPSS-22. The ratio (M: F) for sex distribution and mean and standard deviation for age distribution were computed. T-tests were applied for ESR and Frankel grading in both groups with $\mathrm{p}=<0.05$ considered statistically significant. 


\section{RESULTS}

\section{Gender Distribution}

There were $37(54.41 \%)$ males and 31 (45.59\%) females.

\section{Age Range}

Mean age was $34.84 \pm 10.6$ years.

\section{Clinical Presentation}

The thoracic spine was the commonest site of involvement in $33(48.5 \%)$ patients [18 (53.3\%) patients in Group A and 15 (43.3\%) patients in Group B], followed by lumbar spine in 20 (20.8\%) patients, dorso-lumbar in seven $(10.3 \%)$ patients and cervical spine in only four $(5.88 \%)$ patients (Figure 1). The ESR fell from $85 \mathrm{~mm} / \mathrm{hr}$ to $24.46 \mathrm{~mm} / \mathrm{hr}$ in Group A and $41.92 \mathrm{~mm} / \mathrm{hr}$ in Group B, at the end of six months given in Figure $2(p=0.0124)$. Overall improvement in Frankel grade was seen in $25(73.5 \%)$ patients in Group A and $12(35.3 \%)$ in group B. In group A, improvement from preoperative grade $\mathrm{A}$ in two $(8 \%)$, grade B in three (12\%), grade C in $12(48 \%)$, Grade D in seven (23\%) patients, $\mathrm{p}=0.0000$ (Table 1) while

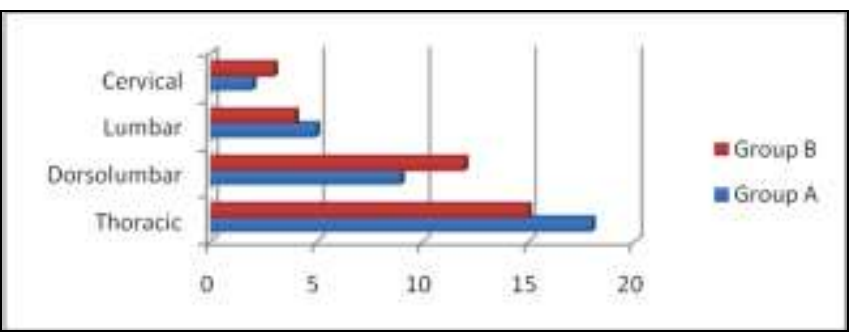

Fig. 1: Spinal Levels Involved.

Table 1: Pre-op and Post-operative Frankel Grade in Group A.

\begin{tabular}{|c|c|c|c|c|c|c|c|}
\hline Pre-Operative & \multicolumn{7}{|c|}{ Post-Operative } \\
\hline Frankel Grade & $\mathbf{A}$ & B & C & D & $\mathbf{E}$ & $\begin{array}{c}\text { Total } \\
\text { (n) }\end{array}$ & \multirow{7}{*}{$\begin{array}{l}\mathrm{p} \text { value } \\
<0.0001\end{array}$} \\
\hline A & 3 & 1 & 1 & & & 5 & \\
\hline B & & & 1 & 2 & & 3 & \\
\hline $\mathrm{C}$ & & & & 2 & 10 & 12 & \\
\hline $\mathrm{D}$ & & 1 & & 2 & 7 & 10 & \\
\hline $\mathrm{E}$ & & & & & 4 & 4 & \\
\hline Total (n) & 3 & 2 & 2 & 6 & 21 & 34 & \\
\hline
\end{tabular}

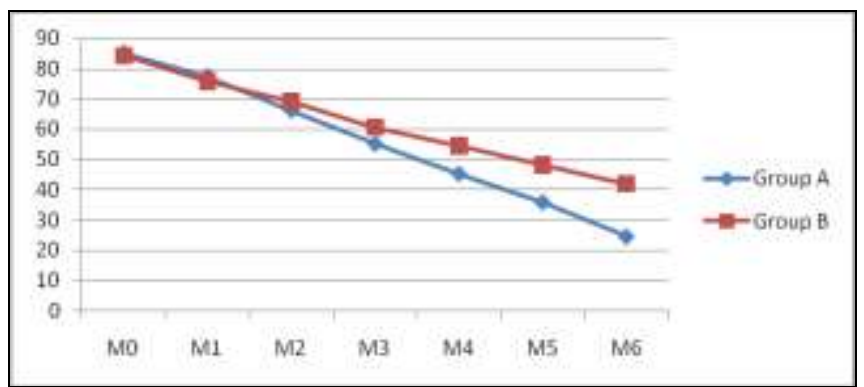

Fig. 2: ESR Trend Over 6 Months of Treatment.

eight $(23.5 \%)$ patients remained same and only one (2.5\%) deteriorated. In Group B, $16(47 \%)$ patients remained same and six (17.6\%) deteriorated (Table 2).

Table 2: Pre-operative and post-operative Frankel Grade in Group B.

\begin{tabular}{|c|c|c|c|c|c|c|c|}
\hline Pre-Operative & \multicolumn{6}{|c|}{ Post-Operative } & p value \\
\hline Frankel Grade & $\mathbf{A}$ & B & $\mathbf{C}$ & D & $\mathbf{E}$ & $\begin{array}{c}\text { Total } \\
\text { (n) }\end{array}$ & \multirow{7}{*}{$<0.0001$} \\
\hline$A$ & 1 & & & & & 1 & \\
\hline B & & 1 & 1 & & & 2 & \\
\hline$C$ & & 2 & 2 & 3 & 2 & 9 & \\
\hline$D$ & & 1 & 1 & 7 & 5 & 14 & \\
\hline E & & & 3 & & 5 & 8 & \\
\hline TOTAL (n) & 1 & 4 & 7 & 10 & 12 & 34 & \\
\hline
\end{tabular}

\section{Complications}

Major complications encountered were respiratory infections in four $(10 \%)$ and wound infection in two $(5 \%)$ patients. One patient deteriorated from baseline neurological status after surgery while none expired.

\section{DISCUSSION}

Caries spine constitutes nearly half the cases of extra pulmonary tuberculosis. Patients belong to under privileged strata of the society with limited financial resources and often present at the advance stage of the disease. The mean age was $34.84 \pm 10.6$ years as compared to Ningkui et $\mathrm{al}^{8}$ study with ages between 17-72 years old (average $38.8 \pm 15.6$ years). There were a total of $37(54.41 \%)$ males and $31(45.59 \%)$ females with $22(33.35 \%)$ males and $12(17.65 \%)$ females in Group A whereas there was a female preponderance with 19 (27.94\%) patients in Group B. 
The dorsal spine being the longest spinal segment and in close proximity to the chest, is predisposed to being the commonest site of involvement. A study by Turgut, ${ }^{9}$ found the commonest level was thoracic spine $(55.2 \%)$ followed by lumbar spine $(22.8 \%)$. Similarly, in our study, dorsal spine involvement was commonest in $18(53.3 \%)$ patients in Group $\mathrm{A}$ and 15 (43.3\%patients in Group B, followed by lumbar spine in $21(20.8 \%)$ patients, dorso-lumbar in 9 (Group A $8.82 \%$ Group B $11.76 \%$ ) and cervical spine in only 5 $(5.88 \%)$ patients (as shown in Figure 1). This distribution appears to be similar in both studies and consistent with findings by other studies. ${ }^{10,11}$

Few studies have considered ESR as a main prognostic factor despite its value as a marker of disease activity and in prognostication. Robert $\mathrm{G}$ et $\mathrm{al}^{12}$ found mean ESR at presentation was $64.5 \mathrm{~mm} / \mathrm{hr}$ which decreased to $20.5 \mathrm{~mm} / \mathrm{hr}$ by end of treatment. In our study, ESR remained the best prognostic index in both treatment arms. In Group A, the mean ESR was $85.29 \mathrm{~mm} / \mathrm{hr}$ at presentation and dropped to 24.46 $\mathrm{mm} / \mathrm{hr}$ while in Group B, it reduced to $41.92 \mathrm{~mm} / \mathrm{hr}$ from $84.33 \mathrm{~mm} / \mathrm{hr}$ at the end of 6 months (as shown in Figure 2). This suggests that the eradication of active disease was faster in group A as compared to group B.

The aims of surgery are to eradicate active TB lesion(s), achieve neural decompression, restore spinal stability and correct overt deformity. Neurological deficit or worsening, paraplegia, bony deformity, paravertebral collection and failure of medical treatment can be the surgical indications for caries spine. ${ }^{13}$ If the reason for surgery is to prevent kyphosis, its best to operate early when the kyphosis is not excessive, with no proven benefit in late stages. ${ }^{14}$ Compared to thoracic spine, lumbar caries seems to demonstrate less risk of kyphotic deformity. ${ }^{15}$ Literature review reveals that patients with minimum neurological deficit and undergoing earlier surgery fare better than patients with severe deficits and later surgery. Most patients in our study belonged to rural areas with minimal access to good health care and almost always present at late stage with complications.

Many studies focus on the surgical management in caries spine. A Cochrane data base review on Jutte PC and Van Jiang studies assessing 331 patients compared medical treatment and surgery with medical treatment alone for treating active tuberculosis. ${ }^{16}$ Another study by Bhandari A et al. assessed 38 patients with caries spineand found that surgery was indicated for patients younger than 15 years with $>30$ degree deformity, deformity progression despite conservative treatment and no neurological improvement despite antibiotic therapy. ${ }^{17}$

To access and decompress the thoracic spine, the best approach is anterior (transthoracic) because it allows direct access to the infected tissue, thereby providing good decompression ${ }^{18}$ which was performed in fourteen $(45.59 \%)$ of our patients in Group A. This was combined with stabilization with Webb Morley stabilization system as it is comparatively inexpensive. Inlay osteoinductive rib graft was applied after decompression and fixation for inducing osteoblastic activity. However, anterior approaches carry higher risk in tuberculosis patients because of already compromised chest function. Anterior cervical decompression and stabilization with Casper plating was performed in only two $(10.76 \%)$ patients having lesion of cervical cord. Tricortical strut iliac crest graft was used for vertebral fusion after decompression.

Zhong W et al compared the effectiveness of different surgical procedures and showed favorable results for each surgical procedure in terms of neurological recovery and kyphosis correction. ${ }^{19}$ Anterior instrumentation of spine for caries spine has better results for immediate and long term correction of local deformity than the cases where instrumentation was not used. ${ }^{20} \mathrm{Su} \mathrm{SH}$ et al retrospectively studied 48 patients with caries spine over seven years where surgery was performed on 30 $(62.5 \%)$ patients and these had more favorable outcomes. He concluded that combined surgical intervention was superior and longer treatment periods had no additional benefit. ${ }^{21}$ Our results are consistent with this study and show superior recovery in the operative field. Recently, the combined surgical approach and minimal invasive (MIS) have been used for the caries spine with successful results but careful selection of patients is needed. ${ }^{22}$ Anterior decompression enables the direct removal of the infected centre and posterior fixation gives stabilization and correction of deformity. ${ }^{23}$ MIS is another technique with anterior and posterior approaches or can be combined with open surgical procedure, for debridement and fusion but its role is questionable in severe compression. ${ }^{22,24}$

Most patients do not get enough benefit from surgery in terms of neurological improvement. Jain et $\mathrm{al}^{25}$ in a retrospective analysis, reported improvement from preoperative grade B in seven, grade $\mathrm{C}$ in 11 , and Grade $\mathrm{D}$ in 10 patients to improvement into grade $\mathrm{D}$ in six and grade $\mathrm{E}$ in 22 patients at latest follow-up. In comparison, a total of 
$25(73.5 \%)$ patients in Group A and $12(35.3 \%)$ in group B showed statistically significant improvement. In group $\mathrm{A}$, improvement from preoperative grade $\mathrm{A}$ occurred in two $(8 \%)$, grade $\mathrm{B}$ in three $(12 \%)$, grade $\mathrm{C}$ in $12(48 \%)$, Grade D in seven (23\%) patients, $\mathrm{p}=$ 0.0000 (as shown in Table 1) while eight $(23.5 \%)$ patients remained same and only one $(2.5 \%)$ deteriorated. In Group B, 16 (47\%) patients remained same and six (17.6\%) deteriorated (Table 2).

Osmanagic ${ }^{26}$ performed a meta-analysis on caries spine and concluded there were no statistically significant differences for any outcome measures. Among many variables, the most important were the neurological deficit and regained activity level, though the study had small sample size to say whether routine surgery was beneficial. In contrast, we found significant difference between neurological outcomes inboth groups (as shown in Table 1 and 2). Ningkui ${ }^{8}$ found medical treatment lasting $<6$ months [ultrashort course chemotherapy (UCCT)], rather than the traditional 6-18 months, was effective in sustaining TB clearance after surgical debridement.Other studies such as Mirkoohi ${ }^{27}$, Ekinci ${ }^{28}$, Varatharajah and Charles also advocate surgical intervention as having superior results. ${ }^{29}$ Major complications encountered in our study were respiratory infections in four $(10 \%)$ and wound infection in two $(5 \%)$ patients. One patient deteriorated from baseline neurological status after surgery while none expired.

To summarize, a surgical knife alone cannot achieve cure, but serves as an excellent adjuvant in managing complicated disease. It not only appears to decrease the need for long term therapy with its associated side effects and issues like poor compliance but also helps in hastening recovery.

\section{CONCLUSION}

Caries spine is primarily a medical condition with surgery reserved for complications like neurological compromise. A surgical knife appears to decrease the need for long term therapy with its associated side effects and issues like poor compliance. Surgical intervention along with antituberculous therapy was found to be beneficial in patients suffering from caries spine with neurological deficit compared to medical treatment alone and to be recommended to patients desiring rapid recovery.

\section{Limitation}

It is a single center sample with a shorter follow-up.

\section{REFERENCES}

1. Yudoyono F, Dahlan RH, Ompusunggu SE, Arifin MZ. Cervical Spine Intramedullary Tuberculoma; case report. NAAS January, 2014; 10 (5005): 180-82.

2. World Health Organization. Global tuberculosis report 2014 [Internet]. Geneva: World Health Organization; c2014 [cited 2016 Aug 29]. Available from: http://apps.who.int/iris/bitstream/10665/ 137094/1/9789241564809_eng.pdf?ua=1.

3. Moon MS. Tuberculosis of Spine: Current Views in Diagnosis and Management. Asian Spine J. 2014; 8 (1): 97-111. Doi: 10.4184/asj.2014.8.1.97

4. Devi KR, Bhutia R, Bhowmick S, Mukherjee K, Mahanta J, Narain K. Genetic Diversity of Mycobacterium tuberculosis Isolates from Assam, India: Dominance of Beijing Family and Discovery of Two New Clades Related to CAS1_Delhi and EAI Family Based on Spoligotyping and MIRU-VNTR Typing. PLoS ONE, 2015; 10 (12): e0145860.

Doi: 10.1371/journal.pone. 0145860

5. González-Martín J, García-García JM, Anibarro L, Vidal R, Esteban $\mathrm{J}$, Blanquer $\mathrm{R}$ et al. [Consensus document on the diagnosis, treatment and prevention of tuberculosis]. Arch Bronconeumol. 2010; 46 (5): 255 74. Doi: 10.1016/j.arbres.2010.02.010.

6. Terry CS, James H. Beaty, Hodgson AR, Stock FE. Anterior spinal fusion: a preliminary communication on the radical treatment of Pott's disease and Pott's paraplegia. Br J Surg Medical. 2012; 44: 266.

7. Chen YH. Clinical features and outcomes of spinal tuberculosis in southern Taiwan. J MicrobiolImmunol Infect. 2012; 43 (4): 291-300. DOI: 10.1016/S16841182(10)60046-1

8. Ningkui N, Wang Q. 'Clinical and genomic responses to ultra-short course chemotherapy in spinal tuberculosis Experimental and Therapeutic Medicine, 2017; 13: 1681-1688. DOI: 10.3892/etm.2017.4170.

9. Turgut M. Spinal tuberculosis (Pott's disease): its clinical presentation, surgical management, and outcome. A survey study on 694 patients. Neurosurg Rev. 2001; 24 (1): 8-13.

10. Jin W, Wang Q, Wang Z, Geng G. Complete debridement for treatment of thoracolumbar spinal tuberculosis: a clinical curative effect observation. The Spine J. 2014; 14 (6): 964-970.

Doi: 10.1016/j.spinee.2013.07.466.

11. Jiang T, Zhao J, He M, Wang K, Fowdur M, Wu Y. Outcomes and Treatment of Lumbosacral Spinal Tuberculosis: A Retrospective Study of 53 Patients. PLoS ONE. 2015; 10 (6): e0130185. Doi: 10.1371/journal.pone.0130185.

12. Robert G, Jeffrey A, Avery B, Ori D, Therese M, Heather L. et al. Trial of Short-Course Antimicrobial Therapy for Intra-abdominal Infection. N Engl J Med. 2015; 37. Doi: 10.1056/NEJMoa1411162.2:1996-2005. 
13. Hussain I, Khan A, Haroon A, Vohra AH. Surgical Outcome of Anterior Decompression, Grafting and Fixation in Caries of Dorsolumbar Spine. J Coll Physicians Surg Pak. 2015; 25 (10): 730-33.

14. Ahsan K, Sakeb N. 'Single-stage posterior instrumentation for progressive tubercular thoracic and thoracolumbar kyphosis.' J Orthop Surg (Hong Kong). 2016; 24 (3): 344-349. DOI: 10.1177/1602400314.

15. Pan Z, Luo J, Yu L, Chen Y, Zhong J, Li Z1, et al. 'Débridement and Reconstruction Improve Postoperative Sagittal Alignment in Kyphotic Cervical Spinal Tuberculosis.' Clin Orthop Relat Res. 2017; 475 (8): 2084-2091. Doi: 10.1007/s11999-017-5306-9. Epub 2017; 6.

16. Jutte PC, van Loenhout-Rooyackers JH. 'Routine surgery in addition to chemotherapy for treating spinal tuberculosis.' Cochrane Database Syst Rev. 2006; 25: (5): CD004532.

Doi: 10.1002/14651858.CD004532.pub2.

17. Bhandari A, Garg RK, Malhotra HS, Verma R, Singh MK, Jain A, Sharma PK. Outcome assessment in conservatively managed patients with cervical spine tuberculosis. Spinal Cord, 2014; 52: 489-493.

Doi: 10.1038/sc.2014.49.

18. Kadota T, Matsui H, Hirose T, Suzuki J, Saito M, Akaba T, Analysis of drug treatment outcome in clarithromycin-resistant Mycobacterium avium complex lung disease. BMC Infectious Diseases BMC series - open, inclusive and trusted, 2016; 16(1): 31. Doi: 10.1186/s12879-016-1384-7.

19. Zhong W, Xiong G, Wang B, Lu C, Dai Z, Lv G. Surgical Management for Thoracic Spinal Tuberculosis Posterior Only versus Anterior Video-Assisted Thoracoscopic Surgery. PLoS One. 2015; 10 (3): 1-10. e0119759. DOI: 10.1371/journal.pone.0119759.

20. Singh S, Kumaraswamy V, Sharma N, Saraf SK, Khare GN. Evaluation of Role of Anterior Debridement and Decompression of Spinal Cord and Instrumentation in Treatment of Tubercular Spondylitis. Asian Spine J. 2012; 6 (3): 183-93.
21. Su HH, Tsai WC, Lin CY, Lin WR, Chen TC, Lu PL. et al Clinical Features and Outcomes of Spinal Tuberculosis in Southern Taiwan. J MicrobiolImmunol Infect. 2010; 43 (4): 291-300. DOI: $10.1016 / \mathrm{S} 1684-1182(10) 60046-1$.

22. Kandwal P, Garg B, Upendra B, Chowdhury B, Jayaswal A. Outcome of minimally invasive surgery in the management of tuberculous spondylitis. Indian J Orthop. 2012; 46: 159-164.

Doi:10.4103/0019-5413.93680.

23. Turgut M. Spinal tuberculosis (Pott's disease): its clinical presentation, surgical management, and outcome. A survey study on 694 patients. Neurosurg Rev. 2001; 24: 8-13.

24. Kapoor SK, Agarwal PN, Jain BK Jr, Kumar R. Videoassisted tharacoscopic decompression of tubercular spondylitis: clinical evaluation. Spine, (Phila Pa 1976). 2005; 30: E605-E610.

25. Jain A, Jain RK, Kiyawat V. 'Evaluation of Outcome of Transpedicular Decompression and Instrumented Fusion in Thoracic and Thoracolumbar Tuberculosis' Asian Spine J. 2017; 11 (1): 31-36. DOI: 10.4184/asj.2017.11.1.31.

26. Osmanagic A, Emamifar A, Bang JC, Hansen IMJ. A Rare Case of Pott's Disease (Spinal Tuberculosis) Mimicking Metastatic Disease in the Southern Region of Denmark. Am J Case Rep. 2016; 17: 384-388.. DOI: 10.12659/AJCR.897555.

27. Mirkooh M, Vaccaro AR, Yarandi KK, RahimiMovaghar V. Spinal Tuberculosis: Diagnosis and management. Asian Spine J. 2012; 6 (4): 294-308. DOI: 10.4184/asj.2012.6.4.294.

28. Ekinci S, Tatar E, Akpancar S, Bilgic S, Ersen O. Spinal Tuberculosis J of Exp Erim Ental Neuroscience, 2015; 9: 89-90. DOI: 10.4137/JEN.S32842.

29. Varatharajah S, Charles YP, Buy X, Walter A, Steib JP. Orthopaedics\& Traumatology: Surgery \& Research: Update on the surgical management of Pott's disease. Otho \& Traumsurg Research, 2014; 100 (2): 233-239. DOI: 10.1016/j.otsr.2013.09.013.

\footnotetext{
Additional Information

Disclosures: Authors report no conflict of interest.

Ethical Review Board Approval: The study was conformed to the ethical review board requirements.

Human Subjects: Consent was obtained by all patients/participants in this study.

Conflicts of Interest:
}

In compliance with the ICMJE uniform disclosure form, all authors declare the following:

Financial Relationships: All authors have declared that they have no financial relationships at present or within the previous three years with any organizations that might have an interest in the submitted work.

Other Relationships: All authors have declared that there are no other relationships or activities that could appear to have influenced the submitted work.

No funding was available. 
Address for Correspondence:

Farrukh Javeed

Department of Neurosurgery,

Jinnah Postgraduate Medical Centre

Rafiqui Shaheed Road, Karachi-Pakistan

Email: farrukhjavedkhi@gmail.com

\section{AUTHORS CONTRIBUTIONS}

\begin{tabular}{|l|l|l|}
\hline Sr.\# & Author's Full Name & Intellectual Contribution to Paper in Terms of: \\
\hline 1. & Syed Saleem Shah & Study design and methodology. \\
\hline 2. & Farrukh Javeed & Paper writing, referencing, data calculations and \\
\hline 3. & Lal Rehman & Data collection and calculations \\
\hline 4. & Ali Afzal & Analysis of data and interpretation of results etc. \\
\hline 5. & Munawar Ali & Literature review and manuscript writing \\
\hline 6. & Shakeel Ahmed & Analysis of data and quality insurer \\
\hline
\end{tabular}

Date of Submission: 24-04-2020

Date of Revision: 20-7-2020

Date of Online Publishing: 25-09-2020

Date of Print: 30-09-2020 